\title{
ON WEIGHTED BERNSTEIN TYPE INEQUALITY IN GRAND VARIABLE EXPONENT LEBESGUE SPACES
}

\author{
VAKHTANG KOKILASHVILI AND ALEXANDER MESKHI
}

Abstract. In this paper a weighted Bernstein type inequality on derivatives of trigonometric polynomials is established in new function spaces unifying two nonstandard Banach function spaces, in particular, grand and variable exponent Lebegue spaces.

Mathematics subject classification (2010): 26A33, 41A10, 41A25, 42A10.

Keywords and phrases: Bernstein inequality, trigonometric polynomial, grand variable exponent Lebesgue spaces.

\section{REFERENCES}

[1] R. AkgÜN AND V. KokilashVili, Some notes on trigonometric approximation of $(\alpha, \psi)-$ differentiable functions in weighted variable exponent Lebesgue spaces, Proc. A. Razmadze Math. Inst. 161 (2013), 15-23.

[2] R. A. DeVore And G. G. Lorentz, Constructive approximation, Springer-Verlag, Berlin, Heidelberg, 1993.

[3] L. Diening, Maximal function on generalized Lebesgue spaces $L^{p(x)}$, Math. Inequal. Appl., 7, 2 (2004), 245-253.

[4] Z. DitZian And V. Totik, Moduli of smoothness, Springer-Verlag, New York, Berlin, 1987.

[5] X. DuoandikoetXea, Fouries analysis, Graduate Studies in Mathematics, 29, AMS, Providence, Rhode Island, 2001.

[6] A. FiorenzA, Duality and reflexivity in grand Lebesgue spaces, Collect. Math., 51, 2 (2000), 131148.

[7] A. Fiorenza, B. GuPta, P. JAin, The maximal theorem in weighted grand Lebesgue spaces, Studia Math., 188, (2) (2008), 123-133.

[8] L. GReCO, T. IWANIEC, C. SBORDONE, Inverting the p-harmonic operator, Manuscripta Math., 92 (1997), 249-258.

[9] T. IWANIEC, C. Sbordone, On the integrability of the Jacobian under minimal hypotheses, Arch. Rational Mech. Anal., 119 (1992), 129-143.

[10] V. Kokilashvili And A. Meskhi, Maximal and Calderón-Zygmund operators in grand variable exponent Lebesgue spaces, Georgian Math. J., 21, 4 (2014), 447-461.

[11] V. KokilashVILI AND A. Meskhi, Integral operators in grand variable Lebesgue spaces, Proc. A. Razmadze Math. Inst., 162 (2013), 144-150.

[12] O. KovÁciK AND J. RÁKosNík, On spaces $L^{p(x)}$ and $W^{k, p(x)}$, Czechoslovak Math. J. 41, 4 (1991), 592-618.

[13] R. L. Wheeden And A. Zygmund, Measure and integral. An introduction to real analysis, Marcell Dekker, New York and Basel, 1977. 